\title{
Citron Kinase is an essential effector of the Pbl-activated Rho signalling pathway in Drosophila melanogaster
}

\author{
Tetyana Shandala ${ }^{1,2}$, Stephen L. Gregory ${ }^{1,2}$, Hazel E. Dalton ${ }^{1,2}$, Masha Smallhorn ${ }^{1,3}$ and Robert Saint ${ }^{1,3, *}$ \\ ${ }^{1}$ ARC Special Research Centre for the Molecular Genetics of Development, Adelaide University, Adelaide, SA 5005, Australia \\ ${ }^{2}$ School of Molecular and Biomedical Science, Adelaide University, Adelaide, SA 5005, Australia \\ ${ }^{3}$ Molecular Genetics and Evolution, Research School of Biological Sciences, Australian National University, Canberra, ACT 2601, \\ Australia \\ *Author for correspondence (e-mail: robert.saint@anu.edu.au)
}

Accepted 2 August 2004

Development 131, 5053-5063

Published by The Company of Biologists 2004

doi:10.1242/dev.01382

\section{Summary}

Pebble (Pbl)-activated RhoA signalling is essential for cytokinesis in Drosophila melanogaster. Here we report that the Drosophila citron gene encodes an essential effector kinase of Pbl-RhoA signalling in vivo. Drosophila citron is expressed in proliferating tissues but is downregulated in differentiating tissues. We find that Citron can bind RhoA and that localisation of Citron to the contractile ring is dependent on the cytokinesis-specific Pbl-RhoA signalling. Phenotypic analysis of mutants showed that citron is required for cytokinesis in every tissue examined, with mutant cells exhibiting multinucleate and hyperploid phenotypes. Strong genetic interactions were observed between citron and $p b l$ alleles and constructs. Vertebrate studies implicate at least two Rho effector kinases, Citron and Rok, in cytokinesis. By contrast, we failed to find evidence for a role for the Drosophila ortholog of Rok in cell division. We conclude that Citron plays an essential, non-redundant role in the Rho signalling pathway during Drosophila cytokinesis.

Key words: Cytokinesis, Citron Kinase, Rho Kinase, Drosophila, Rho GTPase signalling, Pebble, Rho, GEF

\section{Introduction}

Cytokinesis is the final step in the cell division cycle when two prospective daughter cells are separated by ingression of the plasma membrane between separating chromosomes. Although still poorly understood, the strict spatial and temporal coordination of cytokinesis with the other events of mitosis appears to be mediated by a number of proteins that form a complex regulatory network (for a review, see Guertin et al., 2002). A major component of this network is the Rho small GTPase, which serves as a switch in a wide variety of signal transduction pathways that regulate cytoskeletal dynamics in cellular processes such as cell migration, adhesion, morphogenesis, axon guidance and cytokinesis (Hall, 1998). Guanine nucleotide exchange factors (GEFs) catalyse the formation of the GTP-bound active form of Rho GTPases, which can bind and activate downstream effectors (Hart et al., 1998). It has been hypothesised that the activation of Rho GTPases by particular GEFs specifies the downstream Rho effector proteins and, therefore, the pathway that is activated (for reviews, see Miki et al., 1993; Schmidt and Hall, 2002; Takai et al., 1998). Drosophila pebble ( $p b l)$ and its mouse and human homologues, named Ect2, encode GEFs that specifically activate RhoA signalling during cytokinesis (Prokopenko et al., 1999; Tatsumoto et al., 1999). Downstream effectors of Rho small GTPases in different cellular contexts are starting to be defined. With respect to cytokinesis, the vertebrate Citron Kinase (Citron) is postulated to be an in vivo target of RhoA during cytokinesis. Citron was isolated in a yeast two-hybrid screen as a protein capable of binding preferentially to GTP-bound RhoA (Madaule et al., 1995). It is a member of a conserved family of serine/threonine kinases described in mouse, rat, human and fly (Di Cunto et al., 1998; Eda et al., 2001; Kimura et al., 2000; Liu et al., 2003; Madaule et al., 1995; Madaule et al., 2000; Sarkisian et al., 2002) (Fig. 1). Consistent with a role in activating myosin II during cytokinesis, Citron can phosphorylate the myosin regulatory light chain (MRLC) in vitro (Yamashiro et al., 2003). Citron and the GTP-bound form of Rho localise to the cleavage furrow and midbody during cell division in mouse, rat and human cells (Di Cunto et al., 1998; Eda et al., 2001). Furthermore, inhibition of Rho in HeLa cells by botulinum C3 exoenzyme abolishes Citron transfer from the cytoplasm to the cleavage furrow (Eda et al., 2001; Sarkisian et al., 2002), suggesting strongly that Rho and Citron interact during cytokinesis. Overexpression of truncated Citron in cell culture blocks cytokinesis, though this phenotype is not induced by fulllength or kinase dead protein (Madaule et al., 1998). Embryos homozygous for a mutation in the mouse Citron gene have multinucleate testis and brain cells, indicating a role in cytokinesis (Di Cunto et al., 2002). However, proliferation is not blocked in most tissues, suggesting that other factors may compensate for the loss of Citron. One such candidate is another Rho effector kinase, Rok. The overall domain structure of Rok resembles that of Citron (Fig. 1). Rok has recently been implicated in the control of cytokinesis (Chevrier et al., 2002; Kosako et al., 2000) as inhibition of human Rok was found to 
delay completion of cytokinesis. Consistent with a level of functional redundancy in their involvement in cytokinesis, both Citron and Rok localise to the cleavage furrow during cytokinesis (Madaule et al., 2000), they are both capable of binding to the same region of Rho (Fujisawa et al., 1998; Yamashiro et al., 2003) and they both phosphorylate the regulatory subunit of myosin II in vitro (Ueda et al., 2002). The vertebrate studies are consistent with Citron being a Rho effector during cytokinesis, but the tissue-restricted mutant phenotypes observed in vivo suggest that Citron is not an essential Rho effector for cytokinesis. With the possibility that phenotypes are being masked by redundancy with Rok, it seemed desirable to analyse the role of Citron in Drosophila, which often shows less genetic redundancy than in vertebrates and is more readily amenable to genetic analysis. Here we analyse, in vivo, the properties and functions of the Drosophila homologue of Citron. We demonstrate that citron is expressed specifically in proliferating tissues and is downregulated in differentiating tissues. We find that citron plays a nonredundant role in cytokinesis and, unlike rok, exhibits strong genetic interactions with $p b l$, consistent with a role as a downstream target of the Pebble (Pbl)-activated Rho intracellular signalling pathway during cytokinesis.

\section{Materials and methods}

\section{Constructs used for the generation of transgenic flies}

$U A S$-citronGFP was made by linker ligation and subcloning from the citron EST clone RE26327 into pBD1010 (kindly provided by B. J. Dickson). This construct expresses a fusion of GFP to the $\mathrm{C}$ terminus of Citron, and includes all of the Citron open reading frame (ORF) except the last amino acid, with an additional four amino acids (DRTK) between the Citron ORF and GFP. Expression of this construct with the $d a-G A L 4$ driver does not rescue the lethality of citron transheterozygotes. The GenBank Accession Number for citron is AE003541, locus CG10522. UAS-pbl ${ }^{R N A i 4 A}$ (hereafter $U A S$ - $p b l^{R N A i}$ ) was generated by PCR amplification of two fragments, 1184-2916 bp and 2182-2916 bp of the $p b l$ EST SD01796, and cloning as an inverted repeat with a 298 bp loop into pUAST via a pBluescriptKS+ intermediate.

\section{Fly stocks}

The two citron (cit) alleles used in this study, KG01697 (a P \{ SUPorP ) insertion at position +2 of the 5'UTR) and GS9053 (a UAScarrying pGSV6 insertion at position +53 of the $5^{\prime}$ UTR of CG10522, kindly provided by Toshiro Aigaki, Tokyo Metropolitan University, Japan), are renamed $\mathrm{cit}^{l}$ and $\mathrm{cit}^{2}$ respectively. $D f(3)$ iro-2 is the smallest available deficiency encompassing the citron locus. To confirm that the insertions in these lines gave the phenotypes observed, they were removed by crossing to $\Delta 2-3$ transposase and testing the white-eyed progeny for lethality over $D f(3)$ iro- 2 . Both alleles readily reverted with respect to both the white marker and lethality over the deficiency. We found that $c i t^{2}$ carried a second site lethal on $3 \mathrm{R}$, which we removed by recombination. Ubiquitous expression of citron from the UAS in cit $^{2}$ was driven by daughterlessGal4 (Wodarz et al., 1995). For targeted expression of genes of interest, the yeast Gal4-UAS system was used (Brand and Perrimon, 1993). UAS-citronGFP and UAS-pbl ${ }^{R N A i}$ constructs were placed under the control of several Gal4-expressing constructs: $\mathrm{Kr}$-Gal4 (which expresses GAL4 in T2-A4), prd-GAL4 (drives expression in each alternative segment of the embryo), en-GAL4 (directs expression in the posterior half of each embryonic segment and posterior domain of the larval wing) and $\operatorname{GALAl}(3)^{31-1-31-1 R A}$ (hereafter $G A L^{431-1}$; a neural driver). Unless specified, fly stocks, such as UAS-p35 and
UAS-CD8GFP, were obtained from the Bloomington Drosophila Stock Center (Indiana University, IN, USA).

\section{Histology and cytology}

Antibodies used were: rabbit anti-phosphorylated histone H3 (Upstate Biotechnology, NY, USA), rabbit anti- $\beta$-galactosidase (Rockland Immunochemicals, PA, USA), mAbs 22C10 (anti-Futsch), 3A9 (anti- $\alpha$ Spectrin), ADL101 (anti-Lamin) (Developmental Studies Hybridoma Bank, IA, USA), mAb anti- $\alpha$-tubulin (Sigma-Aldrich, Israel), anti-IgG secondary antibodies conjugated with AP, HRP, Cy3, Lissamine-Rhodamine (Jackson ImmunoResearch Laboratories, PA, USA), or Alexa488, Zenon Tricolor labelling kit \#1 (for mouse antibodies) and rabbit anti-GFP and Phalloidin-Rhodamine (Molecular probes, OR, USA). For tubulin staining, 3-6 hour embryos were fixed for 2 minutes in $33 \%$ formaldehyde, $0.3 \mathrm{M}$ PIPES pH 6.8, $1 \mathrm{mM}$ EGTA, $1 \mathrm{mM} \mathrm{MgSO}_{4}$ before devitellinising in $80 \%$ EtOH and staining according to standard protocols. For karyotyping, third larval instar brains were dissected, squashed and Giemsa stained according to the protocol of Pimpinelli et al. (Pimpinelli et al., 2000). TUNEL assay (Roche Diagnostics, IN, USA) and Acridine Orange staining was used to detect cell death (Chen et al., 1996; Wolff and Ready, 1991). For dissociation, third larval instar brains were dissected in $1 \times$ PBS and incubated in $1 \times$ PBS containing $2.5 \%$ trypsin and Hoechst $33258(10 \mu \mathrm{g} / \mathrm{ml})$ for 3 hours at room temperature with mild agitation. Dissociated live cells were subsequently analysed by Phasecontrast imaging. In situ hybridisation was performed according to Tautz and Pfeifle (Tautz and Pfeifle, 1989). For detection of DIGlabelled riboprobes we used anti-DIG-AP Fab fragment antibodies (Roche Diagnostics, IN, USA). Tissues were viewed with a Zeiss Axiophot, for transmitted light, or for fluorescence, viewed with an Olympus Provis AX70 epifluorescence microscope or a confocal microscope equipped with a BioRad MRC1000 scanhead and a krypton/argon laser.

\section{Yeast two-hybrid analysis of protein interactions}

The yeast two-hybrid plasmid vectors pVP16 and pLexA-NLS (pNLX) (Hollenberg et al., 1995), and the yeast strains L40 (MATa his3-200 trp1-901 leu2-3,112 ade2 LYS2::(lexAop) -HIS3 URA3::(lexAop)8lacZ GAL4 gal80) and AMR70 (same genotype as L40 except MAT $\alpha$ ), were kindly provided by Dr S. Parkhurst (Fred Hutchinson Cancer Research Center, WA, USA). N-terminal VP16-Rho fusion coding sequences were generated with the complete RhoA coding sequence, a dominant negative RhoA-N19 and a constitutively active RhoAG14V (Prokopenko et al., 2000). Four pNLX-citron clones (Citron 14), corresponding to amino acids 14 to 846,160 to 942,887 to 1599 and 1439 to 1854 respectively, were generated. L40 strains harbouring VP16-RhoA expressing plasmids were mated with AMR70 strains containing lexA-Citron-expressing plasmids. Interactions were tested on X-gal (blue) indicator plates (Sambrook et al., 1989).

\section{RNA interference in $\mathbf{S} 2$ cells}

Double stranded RNA to citron was made by amplifying the EST clone RE26327 with the following primers: TAATACGACTCACTATAGGTACTGTTCGCCGTTCTGGA and TAATACGACTCACTATAGGTACTACGTGGCCGCAATAG, then transcribing with T7 polymerase (Megascript kit, Ambion) and annealing overnight. S2 cells were grown and RNA interference (RNAi) performed according to Clemens et al. (Clemens et al., 2000), using 5 or $15 \mu \mathrm{g}$ dsRNA.

\section{Statistical and sequence analyses}

Wing hair analysis was conducted by scoring the number of multihaired versus single-haired cells in 14 identical frames for each genotype. A sample of each genotype was tested for homogeneity using a $\chi^{2} 2 \times 2$ test. The significance of differences between two genotypes in proportions of multihaired cells was evaluated using a $\chi^{2} 2 \times 2$ contingency test (Mather, 1951). Conserved protein domains were identified by pFam (Bateman et al., 2002) and SMART (Letunic 


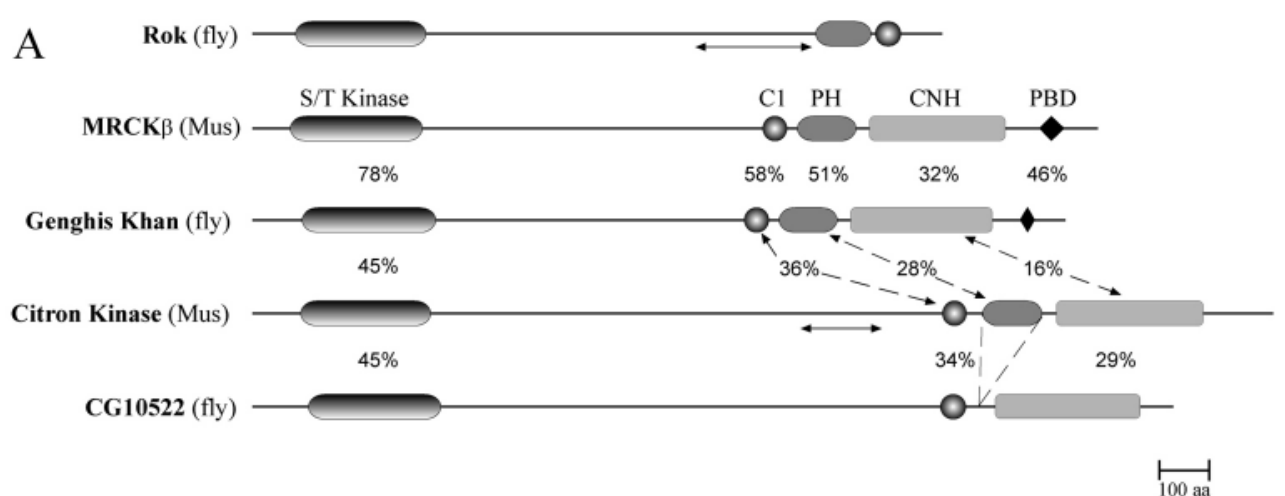

B
Citron 1 (-)
Citron 2 (-)
Citron 3 (-)
Citron $4(+++)$

Fig. 1. Evolutionary conservation of the Citron Kinase family of proteins. (A) The family of Drosophila proteins containing the same conserved domains as vertebrate Citron. Each line is a scale representation of the protein sequence (scale bar represents 100 amino acids), with each conserved domain marked as a different shape. $\mathrm{S} / \mathrm{T}$ Kinase, protein kinase $\mathrm{C}$-class Serine/Threonine kinase domain; $\mathrm{C} 1$, protein kinase $\mathrm{C}$-type diacylglycerol binding domain; $\mathrm{PH}$, Pleckstrin homology phospholipid binding domain; $\mathrm{CNH}$, Citron homology domain of unknown function; PBD, p21-like Cdc42 binding domain. Numbers between the conserved domains indicate the percentage of amino acid identity
to Rho. (B) A C-terminal fragment of between the corresponding domains. Arrowed lines indicate the regions known to be required for binding to Rho. (B) A C-terminal fragment
Citron (Citron 4, amino acids 1439 to 1854) interacts specifically with constitutively active RhoA-G14V. LexA-Citron fusion proteins 1 to 4 , represented by the lines below the domain structure of Citron in A, were assayed for interaction with VP16-RhoA-G14V fusion protein by activation of a lacZ reporter gene in a yeast two-hybrid assay. The strength of interaction is indicated to the right of each Citron fragment, with $(-)$ indicating no interaction and (+++) indicating a strong interaction.

et al., 2002), and alignments were carried out in Clone Manager (Scientific and Educational Software) using FastScan. Sequences used were from the sptrembl database: CG10522: Q9VTY8; Citron (Mus): O88938; Gek: Q9W1B0; MRCKß: O54875; Rok: Q9VXE3.

\section{Results}

\section{Evolutionary conservation of Citron}

The Drosophila genome encodes a set of Serine/Threonine kinases related to Citron (Madaule et al., 1998) that show a similar domain structure: an N-terminal PKC-type kinase domain, a coiled-coil region, a $\mathrm{C} 1$ (lipid binding) domain, $\mathrm{PH}$ (pleckstrin homology) domain and finally a $\mathrm{CNH}$ (Citron homology) domain (Fig. 1A) (Madaule et al., 2000). CG10522 and Genghis khan (gek) are the only Drosophila genes encoding this domain order. By sequence arrangement and function, Gek is more closely related to the Cdc42 effector, MRCK (Fig. 1A) (Luo et al., 1997). CG10522 has no PH domain, although the flanking sequences are conserved. The $\mathrm{PH}$ domain is present in Gek and the vertebrate homologues, suggesting that the common ancestor of these kinases had a $\mathrm{PH}$ domain that was lost in CG10522. The related Rho effector kinase, Rok, lacks a CNH domain and has a different domain order (Fig. 1A). The domain organisation, size, and levels of sequence identity all point to CG10522 encoding the fly homologue of Citron, so hereafter we refer to CG10522 as citron (cit). We tested whether Drosophila Citron, like the mammalian Citron, binds active Rho. In a yeast two-hybrid assay, we found that the C-terminal-most 416 amino acids of Drosophila Citron interact specifically with constitutively active RhoA (Fig. 1B and data not shown). Surprisingly, this interaction region, which encompasses the $\mathrm{CNH}$, is distinct from the Rho interaction domain of mammalian Citron that lies N-terminal to the $\mathrm{CNH}$ and $\mathrm{C} 1$ domains, within a coiled-coil region (Fig. 1A) (Madaule et al., 1998). Thus, although the interaction between Citron and active RhoA is functionally conserved, the interaction domain appears to be different.

\section{Drosophila citron is expressed in proliferative tissues and downregulated in differentiating cells}

Patterns of gene expression can provide clues to gene function. In situ hybridisation showed that Drosophila citron transcripts occur in nurse cells during oogenesis and ubiquitously in early blastoderm embryos (Fig. 2A,B). This indicates the presence of a significant maternal store of transcript. The maternal transcripts persist only until germ band extension, as transcripts are not seen after this stage in embryos lacking zygotic citron (compare Fig. 2C and 2D). With the progression of embryogenesis, citron transcripts are restricted to cells in the central and peripheral nervous systems (CNS and PNS respectively, Fig. 2E-H). citron expression is gradually lost from the CNS and PNS, correlating with differentiation within these tissues (Jan and Jan, 1993). In third instar larvae, citron transcripts were uniformly distributed in all imaginal discs, with the exception of the posterior, differentiating region of the eye disc (data not shown). This pattern of expression, which is initially ubiquitous then restricted to the nervous system (Foe et al., 1993) is very similar to that observed for known cell cycle genes [e.g. three rows, D'Andrea et al. (D'Andrea et al., 1993)], consistent with a role for citron in proliferation. The association of citron expression with proliferating tissues contrasts with the widespread expression of another Rho effector kinase rok, and of RhoA, the putative upstream activator of Citron, consistent with Rok and RhoA having roles beyond proliferation (Hariharan et al., 1995).

\section{Citron localisation to the cleavage furrow requires activation of RhoA}

To explore the intracellular localization of Citron, transgenic $U A S$-citron-GFP flies were generated to produce Citron fused 

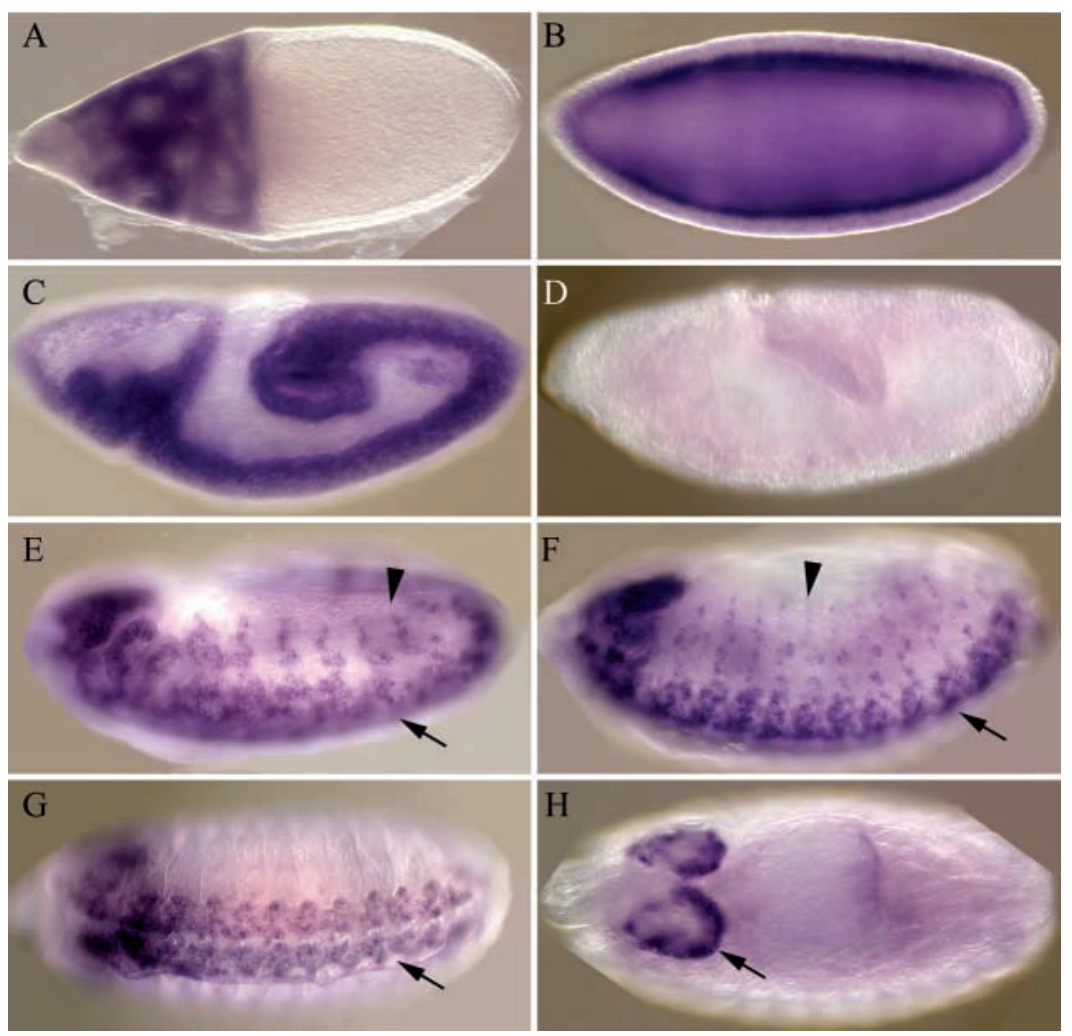

Fig. 2. citron is expressed maternally and in proliferating tissues during Drosophila development. Whole-mount in situ hybridisation with a Drosophila citron DIG-labelled RNA probe. (A) A stage 10A oocyte showing citron transcripts in the nurse cells. (B) Uniform distribution of citron transcripts in a blastoderm embryo. Maternally provided citron mRNA has degraded by stage 9, compare wild-type (C) and homozygous $D f(3)$ iro-2 mutant (D) embryos. (E-H) Zygotic tissue-specific expression of citron in the proliferating CNS (arrow) and PNS (arrowhead) starts during germ-band retraction. Anterior is to the left, dorsal to the top.

\section{Loss of citron function leads to multinucleate embryonic PNS cells}

To test citron function, we initially inhibited Citron expression in Drosophila Schneider line 2 (S2) cultured cells using RNAi. Many citron dsRNA-treated cells ( $~ 30 \%$, compared with $<2 \%$ in controls) became multinucleate (Fig. 3I, comparable to $p b l$ dsRNA treatment in Fig. 3J), indicating that mitosis was not accompanied by cell division. This result is in line with the identification of citron by cell culture-based RNAi screening with a multinucleate phenotype (Kiger et al., 2003; Rogers et al., 2003). To assess whether Citron is required for cytokinesis in vivo, we made use of the available cit $^{\text {KG01697 }}$ and

at the $\mathrm{C}$ terminus to Green Fluorescent Protein (GFP). The Citron-GFP fusion protein expressed in embryos and larval brains was scattered throughout the cytoplasm during interphase (data not shown). In dividing cells, Citron-GFP was observed to accumulate at the constricting membrane following anaphase and persisted in the midbody between divided daughter cells upon completion of cytokinesis (Fig. 3A-D, see Movie 1 in supplementary material). The cleavage furrow is enriched in many proteins that are required for the progression of cell division, including RhoA, MRLC and myosin II (for a review, see Guertin et al., 2002). We confirmed that Citron-GFP localises to this contractile ring by showing an overlap of the GFP signal with a stain for RacGAP50C (data not shown), a known cytokinesis regulator that associates with the contractile ring (Somers and Saint, 2003), and by live imaging of contraction (see Movie 1 in supplementary material). The striking similarity in intracellular localisation of fly, mouse, rat and human homologues of Citron suggests that the function of these proteins during mitosis is conserved (this study) (Di Cunto et al., 1998). Localisation of mammalian Citron to the cleavage furrow during cytokinesis is blocked by treatment with a Rho GTPase inhibitor (Eda et al., 2001). The Rho-GEF, Pbl, targets RhoA during cytokinesis (O'Keefe et al., 2001; Prokopenko et al., 1999). By examining Citron-GFP localisation in a $p b l$ mutant embryo, we would avoid the drastic disruption that could occur if Rho signalling was blocked indiscriminately (Crawford et al., 1998). In the absence of Pbl, Citron-GFP fusion protein did not accumulate at the cleavage furrow at telophase (Fig. 3E-H). These data indicate that Citron accumulates at the contractile ring in response to activation of Rho by the Rho-GEF Pbl. cit $^{G S 9053}$ alleles, which have P-element transposon insertions in the $5^{\prime} \mathrm{UTR}$ of the Drosophila citron locus. We subsequently refer to these alleles as $c i t^{1}$ and cit $^{2}$ respectively. To avoid the possibility of homozygosing second site mutations, all analyses used transheterozygotes between $\mathrm{cit}^{l}, \mathrm{cit}^{2}$ or $D f(3)$ iro-2, a small deficiency spanning the citron locus. All homozygous and transheterozygous genotypes were lethal, showing that citron is essential for Drosophila development. A considerable number of citron transheterozygotes died during larval development, and the remainder died before eclosion. Transheterozygotes between citron alleles and the deficiency did not show an earlier lethal phase or stronger phenotypes in our assays than citron mutant homozygotes or transheterozygotes, indicating that $\mathrm{cit}^{l}$ and $\mathrm{cit}^{2}$ are strong alleles if not genetically null. The insertions were responsible for the lethality observed, as both alleles could be reverted to viability by the expression of $\mathrm{P}$ transposase (see Materials and methods). Furthermore, since the $c^{2}{ }^{2}$ insertion carries a UAS element, we were able to show that ubiquitous citron gene expression rescued $\mathrm{cit}^{2} / \mathrm{Df}(3)$ iro-2 transheterozygotes to viability, confirming that loss of the citron transcript is responsible for the phenotypes we describe. Depletion of maternal deposition of citron using the FLP/FRT ovoD1 system (Chou and Perrimon, 1996) led to female sterility, indicating that Citron is required during oogenesis. To characterize the citron mutants, we initially looked for disruption to neural cell development. As previously shown (Fig. 2), maternal citron seems to be depleted by stage 10, the stage at which embryonic sensory organ precursors commence a wave of cell divisions (Campos-Ortega and Hartenstein, 1997). We reasoned that loss of zygotic citron might have some effect on these PNS cell divisions and on neural divisions in 

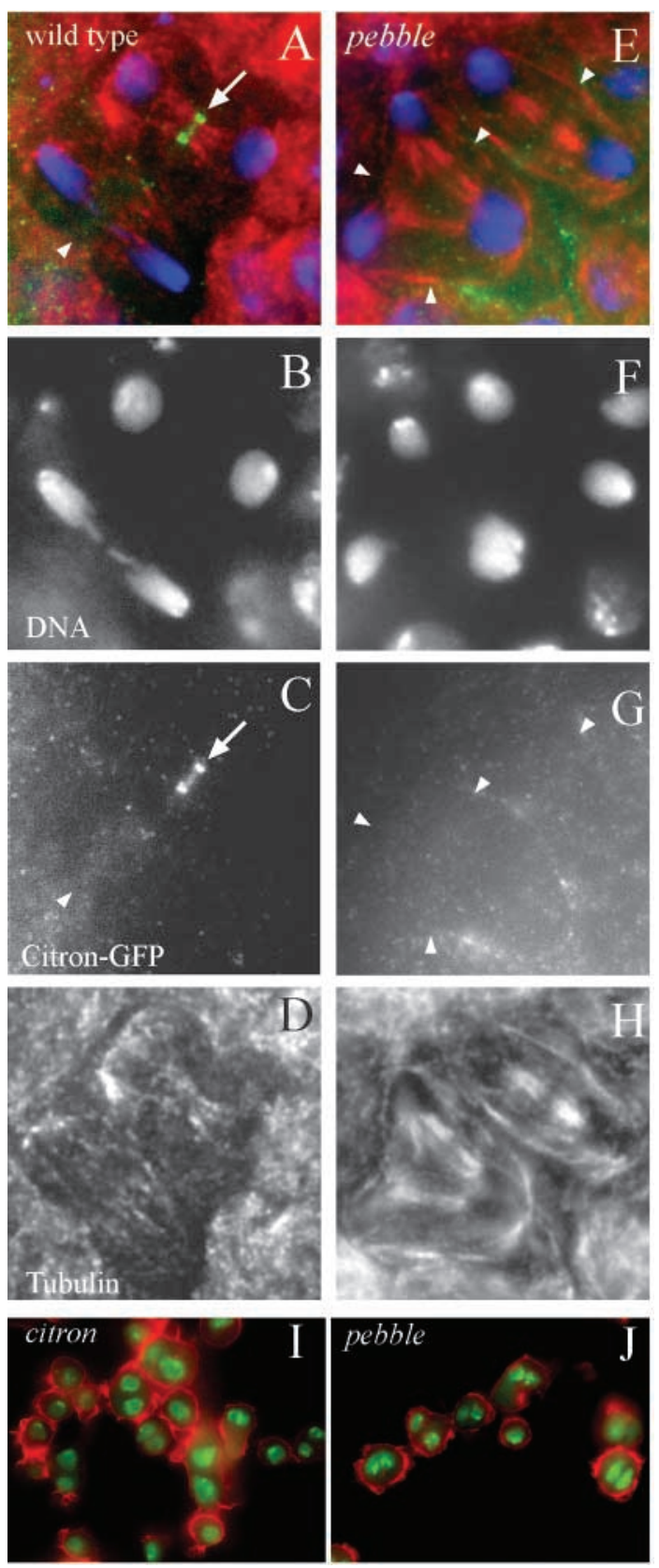

the larva. In wild-type embryos the PNS is organised in distinct, highly stereotyped clusters within each segment (Campos-Ortega and Hartenstein, 1997; Hummel et al., 2000). For instance, the dorsal external sensory (DES) cluster forms a grape-like structure with cells closely linked to each other (Fig. 4A). The lateral chordotonal organ $(\mathrm{CH})$ cluster typically contains five oval-shaped cells of similar size extending parallel processes dorsally (Fig. 4A'). Examination of the PNS in $\mathrm{cit}^{l} / D f(3)$ iro-2 and $\mathrm{cit}^{2} / D f(3)$ iro-2 transheterozygous embryos using the 22C10 monoclonal antibody (Zipursky et al., 1984) revealed a modest disruption to nervous system organization (Fig. 4B, B') with some disorganisation of clusters and defects in axonal projections, suggestive of a role in neuronal morphology and axonogenesis. Similar phenotypes have previously been shown for hypomorphic alleles of $\mathrm{pbl}$, which encodes an upstream activator of the Rho GTPase
Fig. 3. Subcellular localisation of Citron-GFP to the contractile ring during cytokinesis depends on the normal activation of Rho signalling. (A-H) Citron-GFP was expressed in the 3-6 hour embryonic epidermis using paired-Gal4. DNA is stained with Hoechst 33258 (B,F), Citron-GFP is stained with anti-GFP $(\mathrm{C}, \mathrm{G})$, and microtubules are stained with anti- $\alpha$-tubulin antibodies $(\mathrm{D}, \mathrm{H})$. (A,E) Merged images with Citron-GFP stained green, DNA stained blue and microtubules stained red. (A-D) A wild-type embryo showing Citron-GFP in the contractile ring (arrow) as it constricts around the central spindle microtubules. Citron-GFP is not localised in the adjacent anaphase cell that is yet to constrict (arrowhead). (E-G) An embryo mutant for the Rho activator pebble showing typical tetranucleate and binucleate cells and bipolar and tripolar spindles of cells failing cytokinesis. Citron-GFP shows no localisation to the contractile ring in pebble mutant telophase cells. It is found diffusely through the cytoplasm of telophase cells and not at the positions where contractile rings would normally form (arrowheads). (I-J) Drosophila Schneider line 2 cultured cells stained for DNA (green) and actin (red). Incubation with citron dsRNA (I) or dsRNA corresponding to the Rho activator pebble (J) causes the formation of multinucleate cells.

(Salzberg et al., 1994; Salzberg et al., 1997). Importantly, there was a loss of neurons and concomitant appearance of binucleate neurons in approximately $15 \%$ of citron mutant PNS cells (Fig. 4C, C', arrows, E), consistent with the failure of cytokinesis.

\section{Citron mutant larval brains contain polyploid and multinucleate cells}

The presence of maternal citron transcripts and the late embryonic PNS phenotype suggested that maternally-derived Citron permits early proliferation, but is lost later in embryogenesis. After embryogenesis there is little proliferation in the nervous system until the CNS begins to divide rapidly at the end of the second larval instar (Truman et al., 1993), by which stage the zygotic mutant phenotype should be evident. citron mutant larval brains contained massively enlarged nuclei (Fig. 5A,B), DNA stains showing large diffuse aggregates of apparently hyperploid cells. In addition, dissociated mutant larval brain cells from any allelic combination were binucleate at a far higher rate (26/103) than normal (1/100; Fig. 5C). Chromosome preparations from mutant brains (Fig. 5D-F) showed tetraploid metaphase figures (Fig. 5D), confirming that citron mutant brain cells can complete $\mathrm{S}$ phase and enter mitosis following a previously failed mitosis or cytokinesis. We also observed hyperploid cells undergoing anaphase (Fig. 5E), suggesting that a failure of chromosome disjunction was not the primary defect. Furthermore, the frequency of diploid anaphases and telophases was similar in all citron allelic combinations (approximately $37 \%$ of mitotic cells) and did not significantly differ from wild-type control (39\%). Consistent with this, immunohistochemical analysis showed that centrosomes separate normally in the polyploid cells, since we observed an assembly of microtubule spindles apparently emanating from multiple centrosomes (Fig. 5G-G", $\mathrm{H}-\mathrm{H}^{\prime \prime}$ ). Some mutant brain cells were massively hyperploid (Fig. $\left.5 \mathrm{~F}, \mathrm{H}^{\prime}\right)$ showing that in the absence of Citron, brain cells can undergo multiple mitotic cycles without dividing. However, with increasing cell ploidy, microtubules form abnormal spindles (Fig. 5G,H) and chromosomes fail to assemble at the metaphase equator (Fig. 

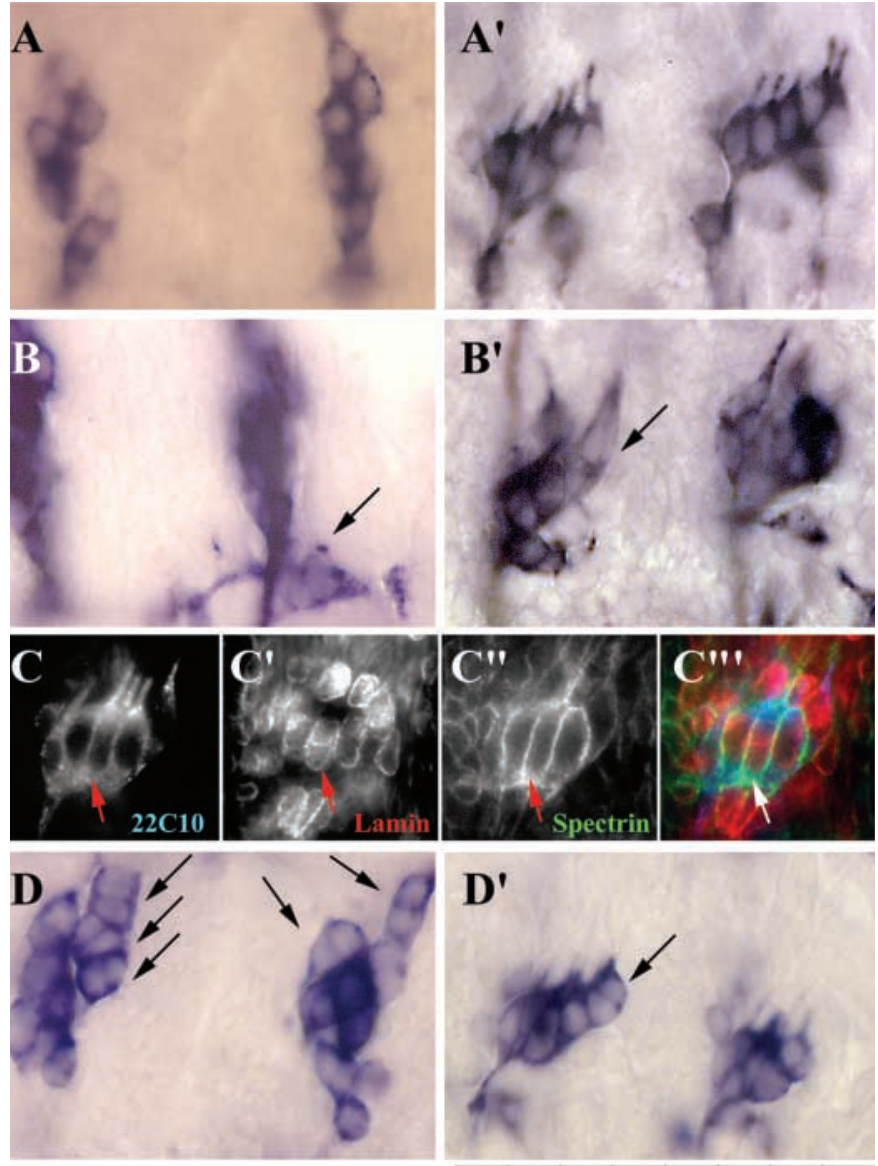

D'

$\mathbf{E}$

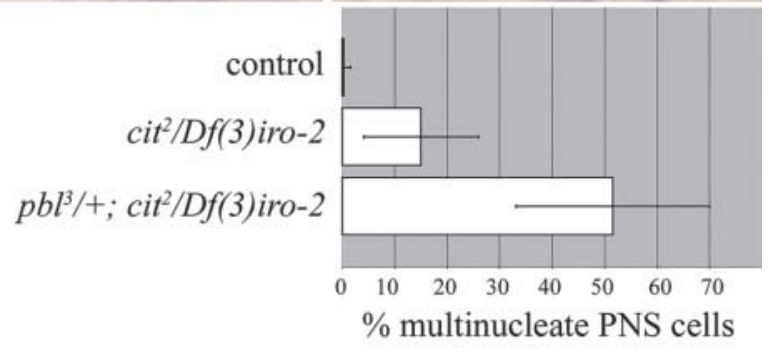

$\left.5 \mathrm{G}^{\prime}, \mathrm{H}^{\prime}\right)$. These defects are clearly the later consequences of an earlier cell division failure, so we conclude that the primary citron larval brain phenotype is a failure of cell division.

\section{Imaginal disc cells mutant for citron exhibit cell division defects accompanied by high levels of apoptosis}

Examination of citron mutant larvae revealed a variable but marked reduction in the size of their imaginal discs (Fig. $6 \mathrm{~A}, \mathrm{~B})$. In line with these observations, we could only generate one or two cell somatic clones of homozygous mutant cells in the wing (data not shown). Cell sizes were not obviously different in the mutants, but wing and leg discs stained with anti-phospho Histone $\mathrm{H} 3$ (anti-PH3) showed a mild reduction in the number of mitotic cells relative to wild-type (down to $60 \%$ of wild-type for $\mathrm{cit}^{1}$ and $77 \%$ for $\mathrm{cit}^{2}$, Fig. 6C,D and data not shown). Since this level of perturbation might not be expected to produce such small discs, we examined the possibility that a stronger cell division phenotype could have been masked by the rapid clearance of mutant cells by
Fig. 4. Citron function during cytokinesis in the Drosophila embryonic PNS depends on Rho activation. Flat preparations of the PNS from abdominal segments of stage 16 embryos stained for the neuronal specific antibody $22 \mathrm{C} 10\left(\mathrm{~A}, \mathrm{~A}^{\prime}, \mathrm{B}, \mathrm{B}^{\prime}, \mathrm{D}, \mathrm{D}^{\prime}\right)$.

$\left(\mathrm{C}-\mathrm{C}^{\prime \prime \prime}\right)$ Embryonic PNS cells stained with: 22C10 (C, blue in $\left.\mathrm{C}^{\prime \prime \prime}\right)$, nuclear envelope marker anti-Lamin $\left(\mathrm{C}^{\prime}\right.$, red in $\left.\mathrm{C}^{\prime \prime \prime}\right)$ and plasma membrane marker anti- $\alpha$ Spectrin $\left(C^{\prime \prime}\right.$, green in $\left.C^{\prime \prime \prime}\right)$. Anterior is to the left and dorsal up. (A,B,D) Dorsal external sensory (DES) cluster area. $\left(\mathrm{A}^{\prime}, \mathrm{B}^{\prime}, \mathrm{C}-\mathrm{C}^{\prime \prime \prime}, \mathrm{D}^{\prime}\right)$ Lateral chordotonal organ $(\mathrm{CH})$ cluster area. $\left(\mathrm{A}, \mathrm{A}^{\prime}\right) w^{1118}$ (control) embryos showing typical organization of the

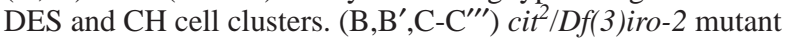
embryos exhibit variable abnormalities, such as absence of cells and multinucleate cells (arrows). The number of nuclei in these cells was estimated by presence of Lamin-positive nuclear envelopes within $\alpha$ Spectrin delineated cellular membrane. A general disorganisation of both clusters and axonal misrouting was also observed.

$\left(\mathrm{D}, \mathrm{D}^{\prime}\right) \mathrm{cit}^{2} / \mathrm{Df}(3)$ iro-2 mutant embryos that are also heterozygous for $p b l^{3}$, showing an increase in the number of multinucleate cells (arrow). (E) To quantitate the effect of loss of one copy of the $p b l$ gene on the cit phenotype, the number of mono- and multinucleate PNS cells in a defined region was scored for each genotype (cells were scored in 30 identical frames). Bars represent the percentage of multinucleate cells in each genotype. Error bars represent one standard deviation.

apoptosis. The TUNEL assay for apoptotic cells and staining with the cell death marker Acridine Orange, revealed an increased level of apoptosis in mutant imaginal discs (Fig. 6E$\mathrm{H})$. Confirmation that apoptosis was clearing cells with a cytokinesis defect came from expression of the apoptosis inhibitor, p35 (Dorstyn and Kumar, 1997), in citron mutant imaginal discs, which led to the accumulation of multinucleate cells (see Fig. S1 in supplementary material).

\section{Genetic interactions confirm Citron as a positive factor in Rho signalling}

As discussed above, Citron has been proposed to act downstream of Rho in the regulation of cytokinesis. However, little in vivo evidence has been found to support this proposition. To test whether Citron participates in Rho signalling we examined genetic interactions between citron and a known regulator of the Rho pathway, the Rho-GEFencoding gene, pebble. The first assay chosen was the ability to modify the moderate citron embryonic PNS phenotype (Fig. $\left.4 \mathrm{~B}, \mathrm{~B}^{\prime}, \mathrm{C}-\mathrm{C}^{\prime \prime \prime}, \mathrm{E}\right)$. We chose $p b l$ mutants rather than Rho mutants because $\mathrm{Pbl}$ appears to be a specific Rho activator for cytokinesis (Prokopenko et al., 1999), whereas loss of Rho also affects many other processes (Crawford et al., 1998). We found that removing one copy of $\mathrm{pbl}$ in cit mutants resulted in a significant reduction in the overall number of cells in the PNS, while most of the remaining cells $(52 \%)$ appeared to be multinucleate (Fig. 4D, $\left.\mathrm{D}^{\prime}, \mathrm{E}\right)$. Therefore, a mild reduction in Pbl-mediated Rho activation during cytokinesis resulted in a significant enhancement of the cit mutant embryonic PNS defects. A complementary approach was to monitor whether under- or overexpression of citron could modify a loss-of-Pbl phenotype. Since strong $p b l$ phenotypes arise too early and are too drastic to be of use, we generated an RNAi construct to inhibit $\mathrm{Pbl}$ synthesis later in development. Expression of this $p b l^{R N A i}$ construct in the posterior half of the wing resulted in a decrease in the size of the corresponding region (Fig. 7C compared with Fig. 7A). Analysis of the affected area revealed 

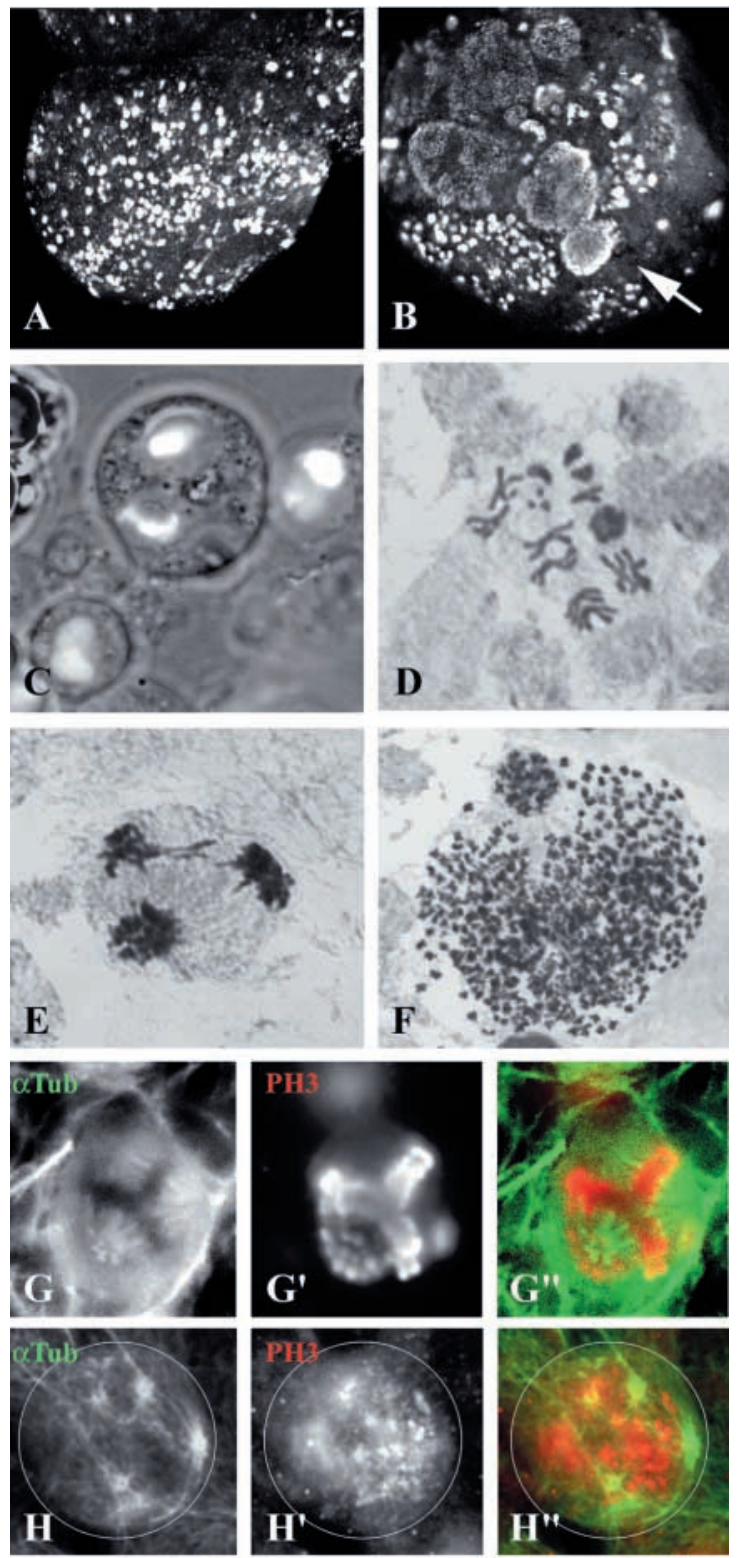

Fig. 5. Loss of Drosophila citron leads to failure of cytokinesis and hyperploidy in the larval brain. Wild-type (A) and cit $^{2} / D f(3)$ iro-2 mutant $\left(\mathrm{B}-\mathrm{H}^{\prime \prime}\right)$ brain lobe tissues from third instar larvae.

(A,B) Immunochemical staining of whole mount brain lobes with anti-phospho Histone H3 (PH3), to detect cells in mitosis, showing large nuclei (arrow) in $c i t^{2} / D f(3)$ iro-2 cells (B) compared to wildtype (A). (C) Binucleate cells dissociated from cit $^{2} / D f(3)$ iro-2 mutant brain lobes stained with Hoechst 33258 to detect DNA (white) overlaid on the phase-contrast image of the cells. (D-F) Mitotic figures from $c i t^{2} / D f(3) i r o-2$ mutant cells, which were squashed and stained with Giemsa dye to detect chromosomes. (D) Tetraploid cell at metaphase. (E) Hyperploid cell showing effective chromosome separation at anaphase. (F) Very highly hyperploid cell. (G-G', H$\left.\mathrm{H}^{\prime \prime}\right)$ High magnification view of individual polyploid cells from mutant brain lobes stained with anti- $\alpha$-Tubulin $(\mathrm{G}, \mathrm{H})$ and anti-PH3 $\left(\mathrm{G}^{\prime}, \mathrm{H}^{\prime}\right) .\left(\mathrm{G}^{\prime \prime}, \mathrm{H}^{\prime \prime}\right)$ Merged images. $\left(\mathrm{G}-\mathrm{G}^{\prime \prime}\right)$ Abnormal metaphase. Three spindle poles are detected by anti- $\alpha$-Tubulin staining (cf pebble mutants in Fig. 3E). (H- $\left.\mathrm{H}^{\prime \prime}\right)$ The cell exhibits a highly polyploid content of condensed DNA and there are eight spindle poles (four in the field of view) associated with defective microtubule spindles that fail to assemble chromosomes at the cell equator $\left(\mathrm{H}^{\prime}\right)$.
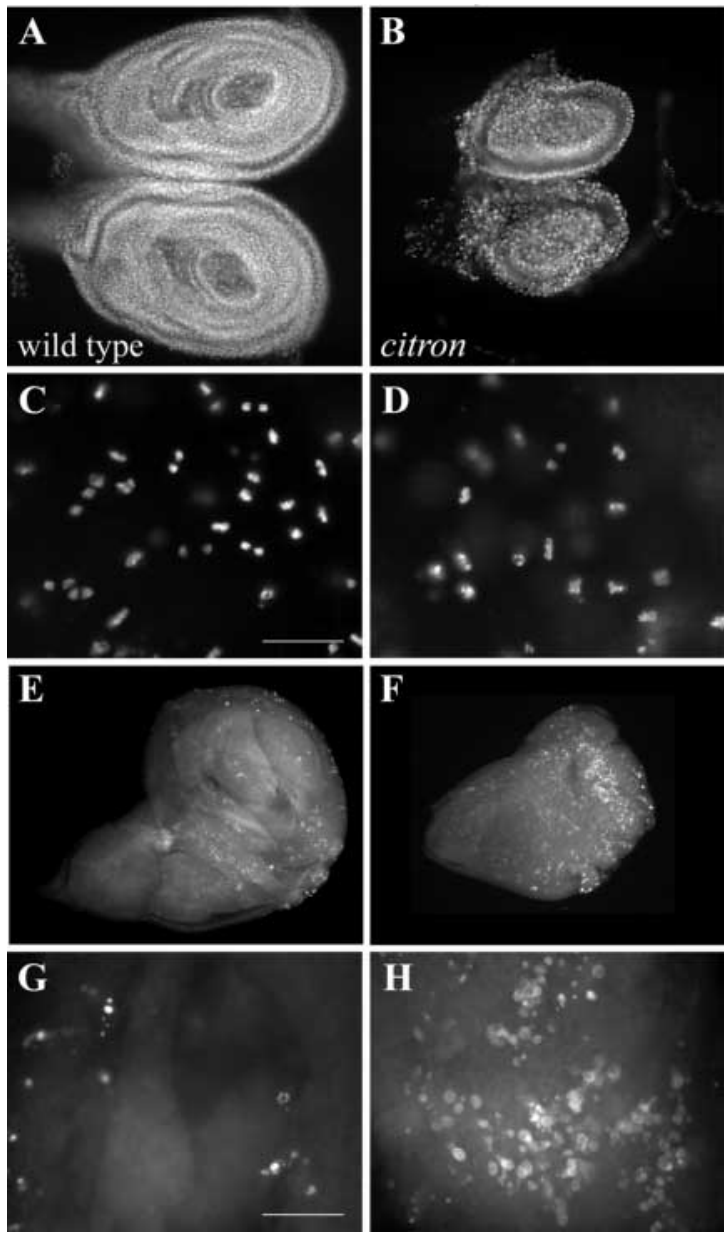

Fig. 6. Loss of Drosophila citron gene function results in a dramatic reduction in imaginal disc size. Imaginal discs from wild-type (A,C,E,G) and $\mathrm{cit}^{2} / \mathrm{Df}(3)$ iro-2 mutant $(\mathrm{B}, \mathrm{D}, \mathrm{F}, \mathrm{H})$ third instar larvae labelled with Hoechst 33258 to detect DNA $(\mathrm{A}, \mathrm{B})$ or with anti-PH3 to detect cells in mitosis (C,D, shown at high magnification) or labelled using TUNEL to detect cells undergoing apoptosis (E,F and high magnification in $\mathrm{G}, \mathrm{H}$ ). Transheterozygous mutant imaginal discs exhibit a dramatic reduction in size (e.g. leg discs shown in B, compare with wild type in A), contain fewer cells progressing through mitosis (compare D with $\mathrm{C}$ ) and many more cells undergoing apoptosis (compare mutant wing disc in $\mathrm{F}$ and $\mathrm{H}$ with wild type in E and G). Scale bars: $25 \mu \mathrm{m}$.

that more than $67 \%$ of cells produce multiple hairs in contrast to the invariably single-haired cells in wild-type (Fig. $7 \mathrm{C}^{\prime}, \mathrm{D}^{\prime}$ compared with $\left.7 \mathrm{~A}^{\prime}, \mathrm{B}^{\prime}\right)$, a phenotype observed when cytokinesis is blocked, for example by inhibition of RacGAP50C (Somers and Saint, 2003). As expected, costaining of pupal wings with phalloidin and the DNA stain Hoechst 33258 revealed that the $p b l^{R N A i}$-expressing cells were abnormally large and typically multinucleate (Fig. 7D), resembling the embryonic phenotype of $p b l$ mutants (Hime and Saint, 1992). The intermediate nature of the en-GAL4>UAS$p b l^{R N A i}$ wing size and multiple hair phenotypes allowed detection of enhancement and suppression by prospective interactors. Firstly, to test the specificity of this assay system we examined the $p b l^{R N A i}$ phenotype in a $R h o A /+$ background. Significant diminution of the $p b l$-depleted region of the wing 
(Fig. 7E) showed that the $p b l^{R N A i}$ phenotype was enhanced by removal of one copy of wild-type RhoA, as seen in other genetic assays for $p b l$ function (O'Keefe et al., 2001). We quantified the multiple hair phenotype in a defined wing region posterior to vein L5 (Fig. 7A, framed area). A significant increase in the proportion of multihaired cells from $67 \%$ to $84 \%$ upon loss of one copy of RhoA (Fig. $7 \mathrm{C}^{\prime}, \mathrm{E}^{\prime}$, Fig. 8E) showed that this assay could detect reductions in the dose of cytokinesis effector genes. Removal of one copy of wild-type citron also reduced the size of the posterior half of the wing in en-GAL4>UAS-pbl ${ }^{R N A i}$ flies (Fig. 8A,B) and enhanced the multiple hair phenotype (up to $86 \%$; Fig. 8E). Identical effects were observed in Df(3)iro-2 heterozygous mutants (Fig. 8E and data not shown). The genetic interactions between loss of function citron and $p b l$ phenotypes support the role of Citron as a Rho effector in cytokinesis. Ectopic expression of citron in various Drosophila tissues generated no dramatic phenotype in wild-type or $p b l^{R N A i}$ backgrounds (Fig. 8C,E) (T.S., unpublished), suggesting that the activity of Rho is rate limiting for Citron function.

\section{Drosophila rok alleles do not interact genetically with the cytokinesis Rho pathway}

It has been suggested that the human Rho effector kinase Rok plays some role in cytokinesis since inhibition of Rok function by Y-27632 led to significantly prolonged ingression of the cleavage furrow, although cytokinesis was eventually completed (Kosako et al., 2000). Drosophila Rok is not required for cytokinesis in wing cells, as somatic mutant rok clones do not display any reduction of size (Winter et al., 2001). However this test does not address the issues of delayed completion of cytokinesis or redundancy between Rok and Citron. Drosophila rok is uniformly expressed throughout development (Mizuno et al., 1999) and so is present in cells expressing citron, making redundant function possible. If the cytokinetic functions of Rok and Citron were redundant, we would expect that halving the dose of one would enhance the cytokinetic mutant phenotype of the other. Since rok mutants have no described cytokinetic phenotype we tested for genetic interactions between $r o k^{2}$, a strong loss-of-function allele (Winter et al., 2001), and Rho signalling in cytokinesis by introducing the $r o k^{2}$ allele into our sensitised $p b l$ RNAi wing assay. In contrast to the enhancement observed by removing one copy of citron (Fig. 8B,E), removal of one copy of rok made no significant difference to the $p b l^{R N A i}$ mutant phenotype (67\% and $65 \%$ respectively, Fig. 8D,E). We therefore failed to find evidence in support of a key role for Rok in Pbl-Rho signalling during cytokinesis.

\section{Discussion}

\section{A conserved requirement for Citron in animal cytokinesis}

We show here that the Drosophila melanogaster citron gene is essential for normal cell division in all of the tissues we examined, including the central and peripheral nervous systems, larval brain cells and larval imaginal tissues. Consistent with a role specifically in cell division, citron transcripts were detected in proliferating tissues, and citron expression was downregulated in post-proliferative cells. This contrasts with the ubiquitous expression of Rho and another
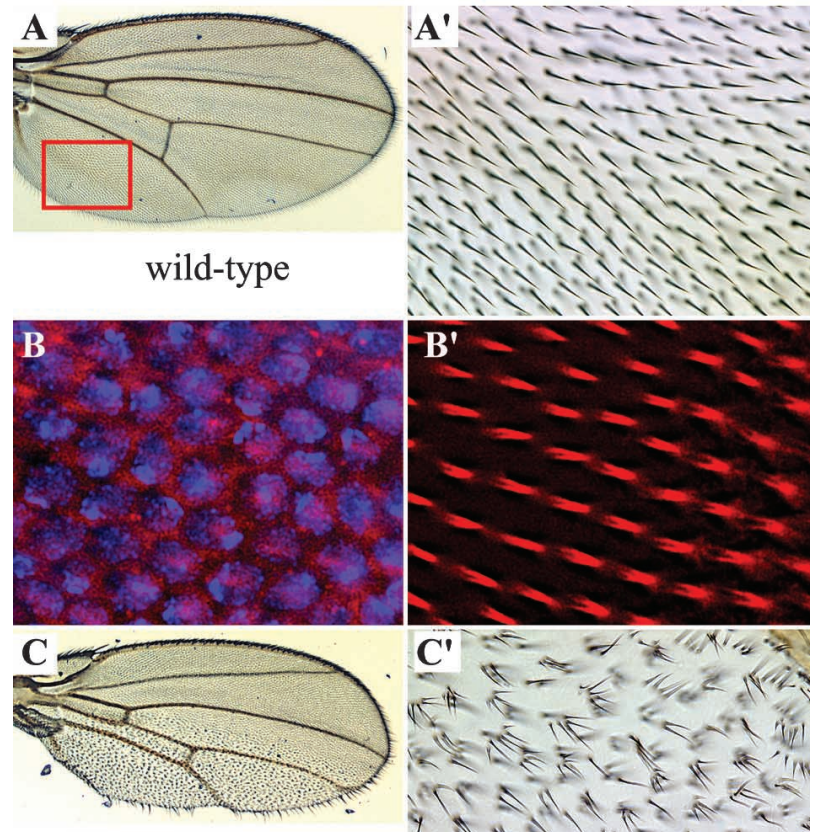

$e n>p b l^{R N A i}$
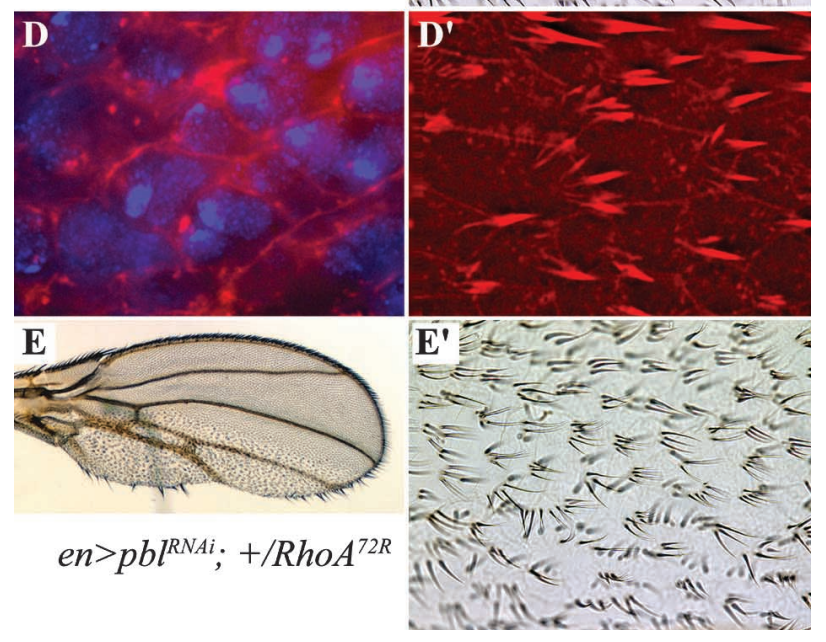

Fig. 7. Reduction of Pebble function in wings by RNA interference causes cytokinetic failure. (A,C,E) Low magnification images of whole adult wings. $\left(\mathrm{A}^{\prime}, \mathrm{C}^{\prime}, \mathrm{E}^{\prime}\right)$ Corresponding high magnification images of the posterior region of the wing (framed in $\mathrm{A}$ ) that was used to evaluate phenotypes (see Fig. 8E). (A, $\mathrm{A}^{\prime}$ ) A wild-type wing showing normal size and shape of the wing $(\mathrm{A})$ and ordered arrangement of hairs $\left(\mathrm{A}^{\prime}\right)$. (B, $\left.\mathrm{B}^{\prime}\right)$ A high magnification of a wild-type pupal wing stained with Phalloidin to detect F-actin (red) and Hoechst 33258 for DNA (blue). Each individual wild-type cell has one nucleus (B) and one prehair F-actin bundle (B'). (C, $\left.\mathrm{C}^{\prime}\right)$ An en$G A L A>U A S-p b l^{R N A i}$ wing showing diminution of Engrailed-domain of the wing $(\mathrm{C})$ and wing hair phenotype $\left(\mathrm{C}^{\prime}\right)$ resulting from reduced $p b l$ activity. Many en-GAL4>UAS-pbl ${ }^{R N A i}$ adult wing cells have more that one hair. $\left(\mathrm{D}, \mathrm{D}^{\prime}\right)$ A high magnification view of an en-GAL4> $U A S-p b l^{R N A i}$ mutant pupal wing stained with Phalloidin for F-actin (red) and Hoechst 33258 for DNA (blue). Mutant cells show more than one nucleus (D) and prehair F-actin bundles ( $\left.\mathrm{D}^{\prime}\right)$. (E, $\left.\mathrm{E}^{\prime}\right)$ Loss of one copy of $R h o A^{72 R}$ further reduces the Engrailed-specific region of the en-GAL4>UAS-pbl ${ }^{R N A i}$ wing (E) and increases the number of multihaired cells $\left(\mathrm{E}^{\prime}\right)$. The multiple haired cell phenotype is quantified in Fig. 8E. 

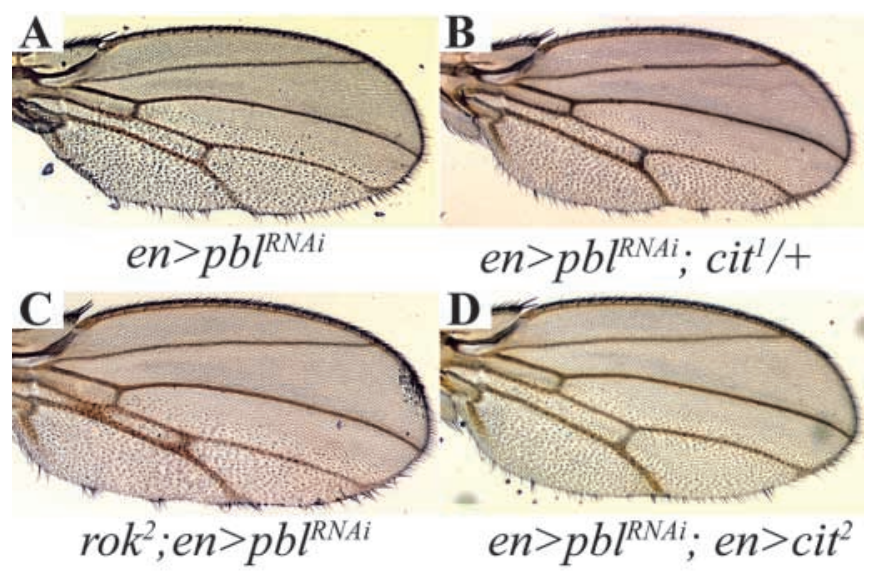

$\mathbf{E}$

$\%$ of multihaired cells

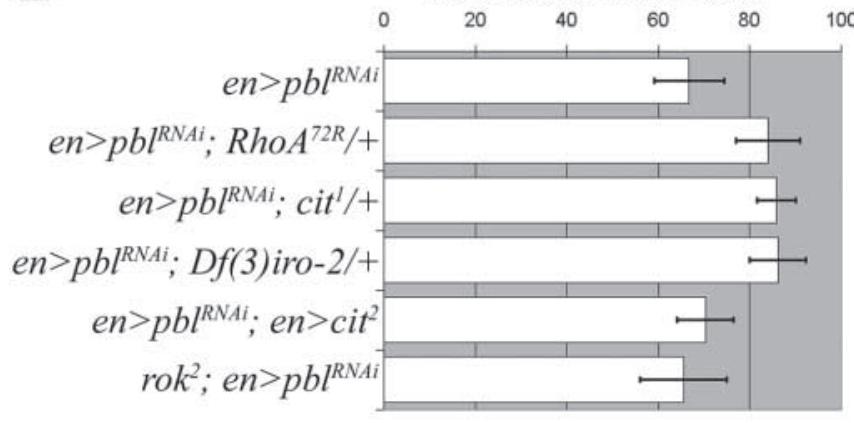

Fig. 8. Citron acts as a positive factor in the Pebble-Rho signalling pathway. Images of whole adult wings. (A) An en-GALA>UAS$p b l^{R N A i}$ wing in a wild-type background. (B) An en- GALA>UAS$p b l^{R N A i}$ wing heterozygous for $\mathrm{cit}^{l}$ shows significant enhancement of the $p b l^{R N A i}$ phenotype. (C) An en-GAL4>UAS-pbl ${ }^{R N A i}$ wing heterozygous for $r o k^{2}$ does not appear be significantly modified. (D) Co-expression of a gain-of-function allele of citron (UAS-cit ${ }^{2}$ ) and $e n-G A L 4>U A S-p b l^{R N A i}$ slightly rescues the $p b l^{R N A i}$ phenotype. (E) The number of multiple haired wing cells in a defined region (posterior to L5, framed in Fig. 7A) was scored for each genotype shown in Fig. 7 and Fig. 8 in order to quantitate the effect. Multiple haired cells were scored in 14 adult wings for each genotype. Bars represent the percentage of multihaired cells in each genotype. Error bars represent one standard deviation. Statistical significance of the difference between two pairs of genotypes was determined using a $\chi^{2}$ $2 \times 2$ contingency test $(P<0.001)$. Significant enhancement of the enGALA >UAS-pbl $l^{R N A i}$ phenotype was seen when flies were heterozygous for $R h o A^{72 R}$, $\mathrm{cit}^{l}$ or $D f(3)$ iro-2 alleles.

Rho effector kinase, Rok, both of which play roles in nonproliferating cells during Drosophila development (Di Cunto et al., 2000; Hariharan et al., 1995; Mizuno et al., 1999). Our analysis of the Drosophila citron mutant phenotype revealed a widespread function in proliferation. In S2 cultured cells treated with citron dsRNA, binucleate cells were observed. Furthermore, the PNS of transheterozygous citron mutant embryos exhibited a loss of neurons and concomitant appearance of multinucleate neurons, similar to the phenotype seen in hypomorphic $\mathrm{pbl}$ and other cell cycle control mutants (Hartenstein and Posakony, 1990; Salzberg et al., 1994). citron mutant larval brain cells also showed a significant number of binucleate cells. These binucleate cells presumably occurred due to the failure of a single round of cell division. Some of the brain cells had undergone multiple rounds of mitosis without cell division, as evidenced by multiple microtubule spindles, an increase in the number of chromosome complements and polyploid anaphase figures, indicating assembly of an effective mitotic spindle. However, with further increases in cell ploidy and centrosome numbers, the spindle did not form properly and chromosomes were lost at metaphase, but the cells evidently continued to cycle, eventually producing giant cells filled with chromosomes. This brain phenotype is similar to spaghetti squash (myosin regulatory light chain) and diaphanous mutant phenotypes (Castrillon and Wasserman, 1994; Karess et al., 1991), but is different to phenotypes of mutants such as makós or aurora that arrest in metaphase (Deák et al., 2003; Glover et al., 1995). We conclude, therefore, that Drosophila Citron has an important and conserved function during cytokinesis. In contrast to larval brain cells and embryonic PNS cells, polyploidy and binucleate cells were not observed in larval imaginal tissues. Rather, the discs were dramatically reduced in size and exhibited high levels of apoptosis. The analysis of other tissues shows that citron is not generally required for cell survival and we found that inhibition of apoptosis in citron mutant discs resulted in the accumulation of multinucleate cells. Therefore, we reason that imaginal cells differ from their brain counterparts by possessing a checkpoint control mechanism that triggers apoptosis following the failure of cell division. The key cytokinetic mutant diaphanous (dia) exhibits similar hyperploid neuroblasts and loss of larval imaginal tissue (Castrillon and Wasserman, 1994).

\section{Citron is a critical Rho effector in the regulation of cytokinesis in vivo}

We have shown that Drosophila Citron, like its mammalian counterparts, is localised to the cleavage furrow during cytokinesis. Many of the important regulators of cytokinesis such as the RhoA GTPase and its activators, and structural components such as myosin and actin, are concentrated in this structure (for a review, see Guertin et al., 2002). Importantly, Drosophila Citron localisation to the cleavage furrow depends on proper activation of the RhoA cytokinesis signalling pathway. In pbl mutant embryos lacking the Pbl Rho-GEF, which activates RhoA during cytokinesis, accumulation of Citron-GFP into the contractile ring does not occur. In vivo confirmation of the importance of Citron function in the Rho cytokinesis signalling pathway came from strong genetic interactions between cit and $p b l$ mutants using two independent genetic assays, one based on the appearance of multinucleate cells in the PNS and one based on a developing wing phenotype. In both cases, loss of function of one of the genes strongly enhanced the phenotype of the other. The citron mutant cytokinesis phenotypes and the enhancement of cit and $p b l$ phenotypes by a reciprocal reduction in their gene activity provides, for the first time, clear genetic evidence for the involvement of Citron in the Rho cytokinesis signalling pathway. The interaction between active Rho and Citron observed in yeast two-hybrid assays (Madaule et al., 1995) (this study) and the loss of Citron localisation to the cleavage furrow in $p b l$ mutant embryos (this study) and in response to Rho inhibitors (Eda et al., 2001) demonstrate that the role of Citron in this pathway is as a downstream effector of Pblactivated Rho. 


\section{Distinct roles in Drosophila for the two Rho effector kinases, Citron and Rok}

The relationship between the two Rho effector kinases, Citron and Rok, is the subject of ongoing discussion (see Li and Minden, 2003). We have demonstrated a non-redundant essential role for Citron in cell division in all Drosophila tissues examined in our study. Drosophila Rok plays an important role in planar cell polarity (PCP) via regulatory phosphorylation of myosin light chain (MLC) and subsequent activation of non-muscle myosin II (Winter et al., 2001). We could not detect any PCP specific phenotype in citron mutants. Moreover, overexpression or loss of one copy of citron had no effect on a PCP-specific dishevelled ${ }^{l}$ mutant phenotype (S.L.G., unpublished) arguing against any involvement of Citron in the control of planar polarity by Rho. Conversely, we could find no evidence for a role for Rok in cell division in Drosophila. Evidence exists for such a role for human Rok, with depletion of its activity in HeLa cells by chemical inhibitors leading to a substantial delay in the completion of cytokinesis (Kosako et al., 2000). However, other studies using the same cells and Rok inhibitor saw no effect or early completion of cytokinesis (Chevrier et al., 2002; Madaule et al., 1998). Higher doses of Rok inhibitor could effectively prevent cytokinesis, but these concentrations also inhibit Citron (Ishizaki et al., 2000). In Drosophila, homozygous rok ${ }^{2}$ eye clones do not differ in size from their homozygous wild-type twin spots (Winter et al., 2001). Our analysis of genetic interactions also failed to produce any evidence of a role for Rok in Rho cytokinesis signalling.

In summary, our genetic analyses have demonstrated an essential role for Drosophila Citron in cell division and provided clear genetic evidence for its function, in vivo, as an effector in Pbl-activated Rho signalling during cytokinesis. Our analysis has also established a set of genetic tools that will allow a detailed dissection of the roles of Citron within the context of a developing organism.

This work was supported by the Australian Research Council. We are very grateful to Dr Carolyn Leach for help with the statistical analysis of our data and to Toshiro Aigaki for giving us access to his GeneSearch stocks and database. We also thank Volkan Evci and Phoebe Vivian for technical support. The monoclonal antibodies 9F8A9 anti-ELAV (developed by G. M. Rubin), 22C10 (developed by $\mathrm{S}$. Benzer) were obtained from the Developmental Studies Hybridoma Bank developed under the auspices of the NICHD and maintained by The University of Iowa, Department of Biological Sciences, IA, USA

\section{Supplementary material}

Supplementary material for this article is available at http://dev.biologists.org/cgi/content/full/131/20/5053/DC1

\section{Note added in proof}

After acceptance of this manuscript, the citron gene described here was reported as the gene sticky by D'Avino et al. (D'Avino et al., 2004).

\section{References}

Bateman, A., Birney, E., Cerruti, L., Durbin, R., Etwiller, L., Eddy, S. R., Griffiths-Jones, S., Howe, K. L., Marshall, M. and Sonnhammer, E. L. (2002). The Pfam protein families database. Nucleic Acids Res. 30, 276-280. Brand, A. H. and Perrimon, N. (1993). Targeted gene expression as a means of altering cell fates and generating dominant phenotypes. Development 118, 401-415.

Campos-Ortega, J. A. and Hartenstein, V. (1997). The Embryonic Development of Drosophila melanogaster. Berlin: Springer.

Castrillon, D. H. and Wasserman, S. A. (1994). Diaphanous is required for cytokinesis in Drosophila and shares domains of similarity with the products of the limb deformity gene. Development 120, 3367-3377.

Chen, P., Nordstrom, W., Gish, B. and Abrams, J. M. (1996). grim, a novel cell death gene in Drosophila. Genes Dev. 10, 1773-1782.

Chevrier, V., Piel, M., Collomb, N., Saoudi, Y., Frank, R., Paintrand, M., Narumiya, S., Bornens, M. and Job, D. (2002). The Rho-associated protein kinase p160ROCK is required for centrosome positioning. J. Cell Biol. 157, 807-817.

Chou, T. B. and Perrimon, N. (1996). The autosomal FLP-DFS technique for generating germline mosaics in Drosophila melanogaster. Genetics 144, 1673-1679.

Clemens, J. C., Worby, C. A., Simonson-Leff, N., Muda, M., Maehama, T., Hemmings, B. A. and Dixon, J. E. (2000). Use of double-stranded RNA interference in Drosophila cell lines to dissect signal transduction pathways. Proc. Natl. Acad. Sci. USA 97, 6499-6503.

Crawford, J. M., Harden, N., Leung, T., Lim, L. and Kiehart, D. P. (1998). Cellularization in Drosophila melanogaster is disrupted by the inhibition of Rho activity and the activation of Cdc42 function. Dev. Biol. 204, 151-164.

D'Andrea, R., Lehner, C., John, U., Stratmann, R. and Saint, R. (1993). The three rows gene of Drosophila melanogaster encodes a novel protein required for chromosome separation during mitosis. Mol. Biol. Cell. 4, 1161-1174.

D'Avino, P. P., Savoian, M. S. and Glover, D. M. (2004). Mutations in sticky lead to defective organization of the contractile ring during cytokinesis and are enhanced by Rho and suppressed by Rac. J. Cell Biol. 166, 61-71.

Deák, P., Donaldson, M. M. and Glover, D. M. (2003). Mutations in makos, a Drosophila gene encoding the $\mathrm{Cdc} 27$ subunit of the anaphase promoting complex, enhance centrosomal defects in polo and are suppressed by mutations in twinstar, which encodes a regulatory subunit of PP2A. J. Cell Sci. 116, 4147-4158.

Di Cunto, F., Calautti, E., Hsiao, J., Ong, L., Topley, G., Turco, E. and Dotto, G. P. (1998). Citron Rho-interacting kinase, a novel tissue-specific ser/thr kinase encompassing the Rho-Rac-binding protein Citron. J. Biol. Chem. 273, 29706-29711.

Di Cunto, F., Imarisio, S., Camera, P., Boitani, C., Altruda, F. and Silengo, L. (2002). Essential role of citron kinase in cytokinesis of spermatogenic precursors. J. Cell Sci. 115, 4819-4826.

Di Cunto, F., Imarisio, S., Hirsch, E., Broccoli, V., Bulfone, A., Migheli, A., Atzori, C., Turco, E., Triolo, R., Dotto, G. P. et al. (2000). Defective neurogenesis in citron kinase knockout mice by altered cytokinesis and massive apoptosis. Neuron 28, 115-127.

Dorstyn, L. and Kumar, S. (1997). Differential inhibitory effects of CrmA, P35, IAP and three mammalian IAP homologues on apoptosis in NIH3T3 cells following various death stimuli. Cell Death Differ. 4, 570579 .

Eda, M., Yonemura, S., Kato, T., Watanabe, N., Ishizaki, T., Madaule, P. and Narumiya, S. (2001). Rho-dependent transfer of Citron-kinase to the cleavage furrow of dividing cells. J. Cell Sci. 114, 3273-3284.

Foe, V. E., Odell, G. M. and Edgar, B. A. (1993). Mitosis and Morphogenesis in the Drosophila embryo: point and counterpoint. In The Development of Drosophila melanogaster (ed. M. Bate and A. Martinez Arias), pp. 149-300. Cold Spring Harbour, NY: Cold Spring Harbor Laboratory Press.

Fujisawa, K., Madaule, P., Ishizaki, T., Watanabe, G., Bito, H., Saito, Y., Hall, A. and Narumiya, S. (1998). Different regions of Rho determine Rhoselective binding of different classes of Rho target molecules. J. Biol. Chem. 273, 18943-18949.

Glover, D. M., Leibowitz, M. H., McLean, D. A. and Parry, H. (1995). Mutations in aurora prevent centrosome separation leading to the formation of monopolar spindles. Cell 81, 95-105.

Guertin, D. A., Trautmann, S. and McCollum, D. (2002). Cytokinesis in eukaryotes. Microbiol. Mol. Biol. Rev. 66, 155-178.

Hall, A. (1998). Rho GTPases and the actin cytoskeleton. Science 279, 509514.

Hariharan, I. K., Hu, K.-Q., Asha, H., Quintanilla, A., Ezzell, R. M. and Settleman, J. (1995). Characterisation of rho GTPase family homologues in Drosophila melanogaster: overexpressing Rho1 in retinal cells causes a late developmental defect. EMBO J. 14, 292-302.

Hart, M. J., Jiang, X., Kozasa, T., Roscoe, W., Singer, W. D., Gilman, A. G., Sternweis, P. C. and Bollag, G. (1998). Direct stimulation of the 
guanine nucleotide exchange activity of p115 RhoGEF by Galpha13. Science 280, 2112-2114.

Hartenstein, V. and Posakony, J. W. (1990). Sensillum development in the absence of cell division: the sensillum phenotype of the Drosophila mutant string. Dev. Biol. 138, 147-158.

Hime, G. and Saint, R. (1992). Zygotic expression of the pebble locus is required for cytokinesis during the postblastoderm mitoses of Drosophila. Development 114, 165-171.

Hollenberg, S. M., Sternglanz, R., Cheng, P. F. and Weintraub, H. (1995). Identification of a new family of tissue-specific basic helix loop-helix proteins with a two-hybrid system. Mol. Cell Biol. 15, 3813-3822.

Hummel, T., Krukkert, K., Roos, J., Davis, G. and Klambt, C. (2000). Drosophila Futsch/22C10 is a MAP1B-like protein required for dendritic and axonal development. Neuron 26, 357-370.

Ishizaki, T., Uehata, M., Tamechika, I., Keel, J., Nonomura, K., Maekawa, M. and Narumiya, S. (2000). Pharmacological properties of Y-27632, a specific inhibitor of Rho-associated kinases. Mol. Pharmacol. 57, 976-983.

Jan, Y. N. and Jan, L. Y. (1993). The peripheral nervous system. In The Development of Drosophila melanogaster (ed. M. Bate and A. Martinez Arias), pp. 1207-1244. Cold Spring Harbour, NY: Cold Spring Harbor Laboratory Press.

Karess, R. E., Chang, X. J., Edwards, K. A., Kulkarni, S., Aguilera, I. and Kiehart, D. P. (1991). The regulatory light chain of nonmuscle myosin is encoded by spaghetti-squash, a gene required for cytokinesis in Drosophila. Cell 65, 1177-1189.

Kiger, A., Baum, B., Jones, S., Jones, M., Coulson, A., Echeverri, C. and Perrimon, N. (2003). A functional genomic analysis of cell morphology using RNA interference. J. Biol. 2, 27.

Kimura, K., Tsuji, T., Takada, Y., Miki, T. and Narumiya, S. (2000). Accumulation of GTP-bound RhoA during cytokinesis and a critical role of ECT2 in this accumulation. J. Biol. Chem. 275, 17233-17236.

Kosako, H., Yoshida, T., Matsumura, F., Ishizaki, T., Narumiya, S. and Inagaki, M. (2000). Rho-kinase/ROCK is involved in cytokinesis through the phosphorylation of myosin light chain and not ezrin/radixin/moesin proteins at the cleavage furrow. Oncogene 19, 6059-6064.

Lee, T. and Luo, L. (1999). Mosaic analysis with a repressible neurotechnique cell marker for studies of gene function in neuronal morphogenesis. Neuron 22, 451-461.

Letunic, I., Goodstadt, L., Dickens, N. J., Doerks, T., Schultz, J., Mott, R., Ciccarelli, F., Copley, R. R., Ponting, C. P. and Bork, P. (2002). Recent improvements to the SMART domain-based sequence annotation resource. Nucleic Acids Res. 30, 242-244.

Li, X. F. and Minden, A. (2003). Targeted disruption of the gene for the PAK5 kinase in mice. Mol. Cell Biol. 23, 7134-7142.

Liu, H., Di Cunto, F., Imarisio, S. and Reid, L. M. (2003). Citron kinase is a cell cycle-dependent, nuclear protein required for $\mathrm{G} 2 / \mathrm{M}$ transition of hepatocytes. J. Biol. Chem. 278, 2541-2548.

Luo, L., Lee, T., Tsai, L., Tang, G., Jan, L. Y. and Jan, Y. N. (1997). Genghis Khan (Gek) as a putative effector for Drosophila Cdc42 and regulator of actin polymerization. Proc. Natl. Acad. Sci. USA 94, 12963-12968.

Madaule, P., Eda, M., Watanabe, N., Fujisawa, K., Matsuoka, T., Bito, H., Ishizaki, T. and Narumiya, S. (1998). Role of citron kinase as a target of the small GTPase Rho in cytokinesis. Nature 394, 491-494.

Madaule, P., Furuyashiki, T., Eda, M., Bito, H., Ishizaki, T. and Narumiya, S. (2000). Citron, a Rho target that affects contractility during cytokinesis. Microsc. Res. Tech. 49, 123-126.

Madaule, P., Furuyashiki, T., Reid, T., Ishizaki, T., Watanabe, G., Morii, N. and Narumiya, S. (1995). A novel partner for the GTP-bound forms of Rho and Rac. FEBS Lett. 377, 243-248.

Mather, K. (1951). Statistical Analysis in Biology. London: Methuen.

Miki, T., Smith, C. L., Long, J. E., Eva, A. and Fleming, T. P. (1993). Oncogene ect 2 is related to regulators of small GTP-binding proteins. Nature 362, 462-465.

Mizuno, T., Amano, M., Kaibuchi, K. and Nishida, Y. (1999). Identification and characterization of Drosophila homolog of Rho-kinase. Gene 238, 437444.

O'Keefe, L., Somers, W. G., Harley, A. and Saint, R. (2001). The Pebble GTP exchange factor and the control of cytokinesis. Cell Struct. Funct. 26, 619-626.
Pimpinelli, S., Bonaccorsi, S., Fanti, L. and Gatti, M. (2000). Preparation and analysis of Drosophila mitotic chromosomes. In Drosophila Protocols (ed. W. Sullivan, M. Ashburner and R. S. Hawley), pp. 3-23. Cold Spring Harbour, NY: Cold Spring Harbor Laboratory Press.

Prokopenko, S. N., Brumby, A., O'Keefe, L., Prior, L., He, Y., Saint, R. and Bellen, H. J. (1999). A putative exchange factor for Rho1 GTPase is required for initiation of cytokinesis in Drosophila. Genes Dev. 13, 23012314.

Prokopenko, S. N., Saint, R. and Bellen, H. J. (2000). Tissue distribution of pebble RNA and Pebble protein during Drosophila embryonic development. Mech. Dev. 90, 269-273.

Rogers, S. L., Wiedemann, U., Stuurman, N. and Vale, R. D. (2003). Molecular requirements for actin based lamella formation in Drosophila S2 cells. J. Cell Biol. 162, 1079-1088.

Salzberg, A., D'Evelyn, D., Schulze, K. L., Lee, J., Stumpf, D., Tsal, L. and Bellen, H. J. (1994). Mutations affecting the pattern of the PNS in Drosophila reveal novel aspects of neuronal development. Neuron 13, 269287.

Salzberg, A., Prokopenko, S. N., He, Y., Tsai, P., Pal, M., Maroy, P., Glover, D. M., Deak, P. and Bellen, H. J. (1997). P-element insertion alleles of essential genes on the third chromosome of Drosophila melanogaster: mutations affecting embryonic PNS development. Genetics 147, 1723-1741.

Sambrook, J., Fritsch, E. F. and Maniatis, T. (1989). Molecular Cloning: A Laboratory Manual. 2nd edn. Cold Spring Harbor, NY: Cold Spring Harbor Laboratory Press.

Sarkisian, M. R., Li, W., Di Cunto, F., D’Mello, S. R. and LoTurco, J. J. (2002). Citron-kinase, a protein essential to cytokinesis in neuronal progenitors, is deleted in the flathead mutant rat. J. Neurosci. 22, RC217.

Savoian, M. S. and Rieder, C. L. (2002). Mitosis in primary cultures of Drosophila melanogaster larval neuroblasts. J. Cell Sci. 115, 3061-3072.

Schmidt, D. J. and Hall, A. (2002). Guanine nucleotide exchange factors for Rho GTPases: turning on the switch. Genes Dev. 16, 1587-1609.

Somers, W. G. and Saint, R. (2003). A RhoGEF and Rho family GTPaseactivating protein complex links the contractile ring to cortical microtubules at the onset of cytokinesis. Dev. Cell 4, 29-39.

Takai, S., Lorenzi, M. V., Long, J. E., Yamada, K. and Miki, T. (1998). Assignment of the ect 2 protooncogene to mouse chromosome band 3B by in situ hybridization. Cytogenet. Cell Genet. 81, 83-84.

Tatsumoto, T., Xie, X., Blumenthal, R., Okamoto, I. and Miki, T. (1999). Human ECT2 is an exchange factor for Rho GTPases, phosphorylated in G2/M phases, and involved in cytokinesis. J. Cell Biol. 147, 921-928.

Tautz, D. and Pfeifle C. (1989). A non-radioactive in situ hybridization method for the localization of specific RNAs in Drosophila embryos reveals translational control of the segmentation gene hunchback. Chromosoma $\mathbf{9 8}$, $81-85$.

Truman, J. W., Taylor, B. J. and Awad, T. A. (1993). Formation of the adult nervous system. In The Development of Drosophila melanogaster (ed. M. Bate and A. Martinez Arias), pp. 1245-1275. Cold Spring Harbour, NY: Cold Spring Harbor Laboratory Press.

Ueda, K., Murata-Hori, M., Tatsuka, M. and Hosoya, H. (2002). Rhokinase contributes to diphosphorylation of myosin II regulatory light chain in nonmuscle cells. Oncogene 21, 5852-5860.

Winter, C. G., Wang, B., Ballew, A., Royou, A., Karess, R., Axelrod, J. D. and Luo, L. (2001). Drosophila Rho-associated kinase (Drok) links Frizzled-mediated planar cell polarity signaling to the actin cytoskeleton. Cell 105, 81-91.

Wodarz, A., Hinz, U., Engelbert, M., and Knust, E. (1995). Expression of crumbs confers apical character on plasma membrane domains of ectodermal epithelia of Drosophila. Cell 82, 67-76.

Wolff, T. and Ready, D. F. (1991). Cell death in normal and rough eye mutants of Drosophila. Development 113, 825-839.

Yamashiro, S., Totsukawa, G., Yamakita, Y., Sasaki, Y., Madaule, P., Ishizaki, T., Narumiya, S. and Matsumura, F. (2003). Citron kinase, a Rho-dependent kinase, induces di-phophorylation of regulatory light chain of myosin II. Mol. Biol. Cell 14, 1745-1756.

Zipursky, S. L., Venkatesh, T. R., Teplow, D. B. and Benzer, S. (1984). Neuronal development in the Drosophila retina: monoclonal antibodies as molecular probes. Cell 36, 15-26. 